Microporosity and delamination mechanisms in thermally sprayed borosilicate glass coatings

Jiming Gao, Yuqing Bao and David T Gawne

London South Bank University

Submitted for publication to Surface and Coatings Technology 


\title{
Microporosity and delamination mechanisms in thermally sprayed borosilicate glass coatings
}

Jiming Gao, Yuqing Bao and David T Gawne*

School of Engineering, London South Bank University, London, SE1 0AA, UK

\begin{abstract}
Conventional enamelling requires both the feedstock powder and the substrate component to be heated one or more times in a furnace at $800-900^{\circ} \mathrm{C}$. The process can degrade the substrate and limit the size of the component to the furnace dimensions, which are serious restrictions on the technology. This study concerns the use of combustion-flame spraying as an alternative technique for enamelling. In this process, the heat source (the flame) is separated from the substrate, which enables much lower substrate temperatures and avoids thermal damage. It also removes the need for furnace treatment and opens up the possibility of on-site enamelling and repair. However, experimental trials showed that thick flame-spray coatings delaminated during cooling and had high microporosities due to quenching stresses at the glass-steel interface and inadequate splat flow of small feedstock particles. The research shows that these adverse mechanisms could be overcome by pre-heating the substrate surface to the dilatometric softening temperature and removing fines from the feedstock powder. The control of these two parameters was found to double the adhesion strength, provide coatings of very similar hardness and fracture toughness to conventional enamel as well as deposit coatings of over $1 \mathrm{~mm}$ in thickness for heavy-duty corrosion protection. Thermal spraying is well established for ceramic and metal coatings but the fundamentally different structure of glasses requires a different approach. An advantage of combustion flame spraying shown up by this research is that the high energy of the flame accelerates the particles to a high velocity and the resulting impact forces promote the flow of the glass. As a result, lower substrate temperatures may be used with reduced risk of degradation or higher viscosity glasses may be
\end{abstract}


deposited with enhanced properties. The influence of the type of thermal-spray technique on coating quality is also discussed.

* Corresponding author. Tel. +44-20-7815-7641; Fax: +44-20-7815-7688

Email address: david.gawne@1sbu.ac.uk (D.T. Gawne). 


\section{Introduction}

Thick glass-based coatings (1-2mm) are used for the heavy-duty corrosion and chemical protection of steel components, such as tanks, pipes and mixers in processing plant for the manufacture of chemical and pharmaceutical products. Processing of these coatings follows conventional enamelling procedure by applying glass particles on the metal component and then heating in a high-temperature furnace to fuse the glass particles into a dense and wellbonded coating [1-3]. In practice, the glass and metal substrate are heated together to the same temperature in the furnace, usually $800-900^{\circ} \mathrm{C}$. Degradation and distortion of the substrate at this temperature needs to be avoided, which limits the choice of material, while the component to be coated clearly needs to fit in the furnace, which limits its size. These limitations restrict the application of glass coatings.

This study investigates the use of thermal spraying as a possible means of overcoming these difficulties. Thermal spraying refers to a generic family of processes consisting of injecting powdered materials into a hot, high-velocity gas jet in which they are heated, accelerated and projected onto a substrate to form a coating. The advantage of thermal spraying is that the gas jet acts as the heat source and is separated from the substrate. This enables the glass particles to be fused in the jet, while the metal substrate is kept at a relatively low temperature. It is a one-stage process, no furnace is required and therefore, in principle, there is no size limit on the substrate [4-8]. In addition, removing the need for a furnace provides the possibility of on-site enamelling and repair.

The work described in this paper is aimed at understanding the underlying mechanisms and producing crack-free, adherent borosilicate glass coatings with a thickness of 1000-1200 $\mu \mathrm{m}$ on an alloy steel by combustion-flame spraying. This thickness is required for the corrosion and chemical protection of steel articles in demanding applications. In practice, the 
requirement of such a high thickness can cause difficulties in manufacture due to cracking and delamination.

Thermal spraying is well-established for the deposition of ceramic and metal coatings [9]. However, these crystalline materials have fundamentally different structures from glasses and this paper shows that a different approach is needed for the deposition of glass coatings. The results obtained on splat flow behaviour, microporosity and the development of mechanical properties are of scientific as well as technological significance.

\section{Experimental Details}

Two borosilicate glasses (G and P1) were used in this investigation. They were conventional borosilicate glasses used for enamelling steel as a means of conferring chemical resistance. Glass G was a groundcoat or primer, which was applied directly on the steel substrate. This glass acted as a bond coat between the steel substrate and the topcoat with an intermediate expansion coefficient. Glass P1 was a topcoat or covercoat, which was applied to Glass $\mathrm{G}$ for promoting chemical resistance. The powders and coatings were amorphous. The powders were provided by Pfaudler Werke GmbH. Table 1 gives the thermal properties of the glasses used as determined by dilatometry. Glass P1 was sieved to give two batches of powders designated as P2 and P3. There were thus three powders to investigate: P1 (the original as-received powder) together with the more refined P2 and $\mathrm{P} 3$ powders.

Combustion-flame spraying was used as a thermal-spray technique in which the hot jet is formed by the combustion of an acetylene-oxygen gas mixture. The substrates were low-alloy steel discs of $105 \mathrm{~mm}$ in diameter and $2.5 \mathrm{~mm}$ in thickness, which were degreased and gritblasted by using alumina grit with a pressure-operated machine to give a surface roughness (Ra) of 5-6 $6 \mathrm{~m}$ immediately before spraying. The surface roughness was measured using a Taylor Hobson instrument. Acetylene was used as the fuel gas with a flow rate of the 
acetylene ranging from 45 to 55 SLPM (standard litres per minute), oxygen as oxidant and compressed air as the powder-carrier gas. A spray distance between the nozzle exit and substrate surface of $250 \mathrm{~mm}$ was used

The thermal history of the glasses during spraying affects the final structure and quality of the coating, and so the temperatures of the coating and substrate during processing were recorded in-situ. The temperature at the coating surface $\left(\mathrm{T}_{\mathrm{s}}\right)$ was measured using an infrared thermometer (MX4 CF Infrared Thermometer, Raytek, UK), which has a response time of 0.1 $\mathrm{s}$ and data collection set at $0.125 \mathrm{~s}$. The temperature at glass-steel interface $\left(\mathrm{T}_{\mathrm{i}}\right)$ was measured using Type $\mathrm{K}$ thermocouples that were attached to the interface before deposition.

The thickness of coatings was measured by PosiTest DFT coating thickness gauge and subsequently confirmed by microstructural observations on the coating cross sections.

The adhesion of the glass coating to the steel substrate was evaluated using a pull-off tensile test, which conforms to ASTM D4541 and BS 3900-E10. Testing was carried out with an Avery universal testing machine (Birmingham, UK) at a crosshead speed of $5 \mathrm{~mm} / \mathrm{minute}$, which measures the tensile force required to detach the coating from the substrate. Three types of failure pattern were recorded during testing. An adhesion failure refers to the fracture at the coating-substrate interface representing the bond strength of the coating to substrate, a cohesive failure by fracture within the coating itself and an adhesive failure by fracture within adhesive or at the adhesive-coating interface. Five specimens from the each powder coating were tested

The microhardness of the coating was measured on the through-thickness cross-sections of the coatings with a Vickers microhardness tester (Struers Duramin-5, UK) under an indentation load of 1 to 5 newtons for a fixed loading time of 15 seconds. 
The fracture toughness of the glass coating was estimated using the Vickers indentation test in which indentations were made on polished cross sections of the coatings under an applied load of $5 \mathrm{~N}$.

The microstructure of cross sections of the feedstock powders and coatings were examined using scanning electron microscopy (S-4300SE, Hitachi Co. Ltd) with energy dispersive spectrometer (Oxford instruments, UK). The coating specimens were cold mounted using epoxy resin and prepared by sequential grinding with 120-2500 mesh grade $\mathrm{SiC}$ abrasive papers. Final polishing was carried out using $1 \mu \mathrm{m}$ and $0.25 \mu \mathrm{m}$ diamond pastes.

Image analysis software (ImageJ) and 200× back-scattered SEM images were used to perform porosity measurements. At least seven images were examined for each type of coatings. The particle size and size distribution of each powder were measured by Laser Diffraction Particle Size Analyzer (LS 200, Beckman Coulter).

\section{Results and Discussion}

\subsection{Delamination of coatings}

The combustion-flame spray deposition conditions were directed at ensuring the glass particles were sufficiently molten but not degraded in the flame. To produce a double-layered structure, $150-200 \mu \mathrm{m}$ of Glass $\mathrm{G}$ was at first deposited directly on the steel substrate that had been pre-heated to $300{ }^{\circ} \mathrm{C}$ immediately prior to deposition to promote bonding of the glass to the steel. This pre-treatment was accomplished by scanning the flame torch over the surface of the substrate. $800 \mu \mathrm{m}$ of Glass P1 was then immediately deposited on Glass G as a topcoat 
in order to form the required double-layered coating system. The thickness of Glass G and Glass $\mathrm{P}$ were controlled by spraying passes during deposition. In this particular coating, five passes were used for the bond coat Glass $G$ and ten passes for the topcoat Glass $P$, as illustrated in Figure 1a.

Figure 1a gives measured the thermal histories of the deposition of the bond coat and topcoat, which shows the pre-heating of the substrate, the surface temperatures of the deposits during deposition and subsequent cooling. The spikes or fluctuations in temperature are caused by the scanning movement of the flame [4]. The temperature drop over the time interval of 80 160 seconds shown in Figure 1a was caused by the changeover of the powders required for the deposition of the topcoat P1 on top of the bond coat G. A dense double-layered deposit was obtained, suggesting that the glass particles were in the molten state on impact with the steel substrate or previously deposited splats. However, the coating was short lived as the glass layers delaminated from the steel substrate and from each other as soon as the temperature fell below $100^{\circ} \mathrm{C}$ during cooling.

Figure $1 \mathrm{~b}$ gives the measured temperatures of the surface and the glass-steel interface of the bond coat (Glass G). It also yields the temperature gradients between the surface and interface. A difference of $460^{\circ} \mathrm{C}$ exists at the beginning of deposition and this falls to $290^{\circ} \mathrm{C}$ at the end due to the build up in temperature at the interface.

The high surface temperatures are caused by the rapid heat transfer from the thermal-spray gas, while the lower interface temperature is due to the rapid conduction to the relatively cold steel substrate. Figure $1 \mathrm{~b}$ indicates that the glass coating experiences thermal shocks or quenching, particularly at the interface during its solidification, which is expected to result in the development of thermal stress at the coating-substrate interface. Once this stress exceeds the adhesion strength of the coating to the substrate (and in the absence of any stress relaxation during cooling), it will cause the coating to delaminate from the substrate. The 
observed adhesion failure of the coating layers during cooling was therefore attributed to the residual stress developed across the interface, which weakened the interfacial bond and resulted in delamination.

Residual stress is a common occurrence in thermal spraying for two principal reasons. Firstly, the coating will inevitably be a dissimilar material to the substrate resulting in an expansion coefficient mismatch, constrained thermal strain and hence thermal stress. Secondly, the inherent rapid cooling of the process will cause severe temperature gradients and residual stresses across coating-substrate interface. The current glasses used for the top coat and interlayer were selected for conventional enamelling such that a smooth and adhering doublelayered coating with a total thickness of $1.2 \mathrm{~mm}$ could be formed from these powders on the steel by oven fusing. In this conventional enamelling process, the glass and substrate were heated together to the fusing temperature of the glass and so no temperature gradients developed. This is not the case in thermal-spray deposition as indicated in Figure $1 \mathrm{~b}$. The development of severe temperature gradients is therefore considered to be a major source of failure and further work was undertaken to address this situation as discussed in the next section.

\subsection{Stress analysis and splat morphology}

There are two major contributors to the overall residual stress of the glass-steel system produced by thermal spraying: (i) quenching stress of splats due to rapid cooling of individual splats; (ii) mismatch stress caused by the constrained thermal strain resulting from the mismatch of the expansion coefficient of the glass with that of the steel substrate.

When a molten glass droplet lands on a rigid substrate or a previously deposited layer, there are four possible outcomes or cases depending upon the substrate temperature $\mathrm{T}_{\text {sub}}$ : 
Case (1) $\quad \mathrm{T}_{\text {sub }}>\mathrm{T}_{\text {melt }}$. Here, the glass will be above its practical melting temperature $\mathrm{T}_{\text {melt }}$ at which the viscosity is $10 \mathrm{~Pa} \mathrm{~s}[10]$. In this case, the splat remains in the molten state and so no quenching stress forms at the glass-steel interface during cooling of the coating. This applies to the conventional oven fusing or enamelling process

Case (2) $\quad \mathrm{T}_{\text {soften }}<\mathrm{T}_{\text {sub }}<\mathrm{T}_{\text {melt }}$. The glass exists between its melting and softening temperatures $\left(\mathrm{T}_{\text {soften }}\right)$ and, at the very least, will flow under its own weight. Any quenching stress that develops is therefore expected to relax and completely dissipate with time.

Case (3) $\quad \mathrm{T}_{\mathrm{g}}<\mathrm{T}_{\text {sub }}<\mathrm{T}_{\text {soften }}$ Here, the glass lies between its glass transition $\left(\mathrm{T}_{\mathrm{g}}\right)$ and dilatometric softening temperature at which the viscosity is $10^{8} \mathrm{~Pa} \mathrm{~s}[10]$. The splat behaves like a viscoelastic body with the result that any quenching stress that develops will relax only partially with time.

Case (4) $\quad \mathrm{T}_{\text {sub }}<\mathrm{T}_{\mathrm{g}}$ The glass will be below its glass transition temperature and will therefore behave as an elastic solid. Quenching stresses will develop and there will be no stress relaxation.

Considering the regime of Case 4 as described above, an incoming glass droplet will flatten into a splat on impact with a rigid surface before it solidifies and splat contraction will be completely prevented. The quenching stress can be estimated from:

$$
\sigma_{q}=E_{C}(T) \alpha_{C}(T)\left(T_{C}-T_{\text {sub }}\right)
$$

where $E_{C}$ is the Young's modulus of the splat, which is a function of the deposit temperature; $\alpha_{\mathrm{s}}$ and $\alpha_{\mathrm{c}}$ are the thermal expansion coefficients of the substrate and coating respectively. $\mathrm{T}_{\mathrm{c}}$ is the temperature of the splat and $\mathrm{T}_{\text {sub }}$ is the temperature of the substrate.

Figure 2 gives the calculated quenching stress of the glass during the deposition using Equation 1 together with the measured thermal history shown in Figure $1 \mathrm{~b}$. The top temperature trace relates to pre-heating the substrate surface to $300^{\circ} \mathrm{C}$ immediately before 
deposition of Glass G (Figure 1), while the bottom trace refers to pre-heating to $400^{\circ} \mathrm{C}$. The value of Young's modulus used in the calculation was 70GPa. Figure 2 presents a simplified estimation as the temperatures used in the calculation are average deposit temperatures at a given measured point and not the true temperatures of the splats. Also, the deposit was considered as an elastic solid and stress relaxation induced by continuous deposition was not considered in the calculation. In fact, the temperature of the deposit recorded (Figure 1) was above the glass transition temperature and as an result, some stress relaxation could take place $[5,6]$. Nevertheless, Figure 2 shows that the thermal stress is high at the beginning (when the droplets first strike the steel substrate) and then gradually decreases with increasing deposition time during which the deposit builds up and the coating-substrate interface temperature rises. The calculation indicates that raising the substrate interface temperature $\mathrm{T}_{\text {sub }}$ can reduce temperature gradients and therefore the quenching stress. As shown in Figure 2, raising $\mathrm{T}_{\text {sub }}$ by $100^{\circ} \mathrm{C}$ enables the calculated stress level to reduce by $35 \%$. In addition, increasing the interface temperature also facilitates stress relaxation as it reduces the viscosity of the glass.

However, a major advantage of thermal spraying over the oven fusing or conventional enamelling process is its ability to keep the substrate at a relatively low temperature and avoid thermal damage or degradation. The temperature of the steel substrate, therefore, plays an important role: it must be low enough to avoid thermal damage but high enough to enable stress relaxation. In order to understand the effect of the substrate temperature more clearly, wipe testing was carried out. This consists of sweeping the flame (loaded with in-flight molten glass particles) over the polished substrate surface sufficiently rapidly to form isolated individual splats. The ability to observe isolated splats facilitates a clearer appreciation of the flow of glass particles than the examination of splats within an aggregated coating. Figure 3 presents the morphologies of Glass P1 splats produced by wipe testing under different substrate temperatures in the range 25 to $700^{\circ} \mathrm{C}$. It shows that extensive splat flow takes place 
at $500^{\circ} \mathrm{C}$ and $540^{\circ} \mathrm{C}$ but little flow at $25^{\circ} \mathrm{C}$, which is consistent with softening temperature of Glass $\mathrm{P} 1$ of $524^{\circ} \mathrm{C}$ (Table 1). The extent of flow at $700^{\circ} \mathrm{C}$ is similar to that at $500^{\circ} \mathrm{C}$ and $540^{\circ} \mathrm{C}$. However, pores were observed in the middle of the splats formed at $700^{\circ} \mathrm{C}$ which was not found in splats formed at the other substrate temperatures. This was considered not to be due to decomposition of the glass since there are no reports of these glasses decomposing during conventional enamelling at the much higher temperatures of $800-900^{\circ} \mathrm{C}$. Instead, it is attributed to entrapped air escaping from beneath the splats due to the lower viscosity of the glass at $700^{\circ} \mathrm{C}$ compared with that at $540^{\circ} \mathrm{C}$ and below in the other splats.

The results in this section indicate that cold substrates $\left(T<T_{\text {soften }}\right)$ limit particle flow and interfacial bonding as well as creating temperature gradients and quenching stresses.

\subsection{Deposition trials}

The bonding of a thermally sprayed coating to a substrate is complex and is related to the materials and deposition conditions used. Nonetheless, whatever mechanism is involved, a primary requirement for bonding is that the glass droplets and steel need to be in close contact. For this to happen, the glass particles need to flow extensively on impact with the substrate so that contact and in-filling is made with the peaks and valleys of the underlying surface profile. In order to understand these mechanisms more clearly, deposition trials were undertaken to investigate the influence of substrate temperature on particle flow, bonding and quenching stress, while avoiding overheating and degradation. The trials involved forming coatings and so the thermal history is different from that in wipe testing. More specifically, the splats undergo the initial spreading stage on impact as they do in the wipe test, but in coating deposition, they then subsequently receive additional heat from the surrounding incoming neighbouring splats and also from the hot gases from the tail end of the scanning flame [4]. 
Case $1\left(T_{\text {sub }}>T_{\text {melt }}\right)$ requires substrate temperatures for conventional enamelling borosilicate grades of very roughly $800-900^{\circ} \mathrm{C}$, depending upon the composition. This is too high for the purposes of substrate pre-heating in this investigation and is excluded. However, Case $3\left(\mathrm{~T}_{\mathrm{g}}\right.$ $\leq \mathrm{T}_{\text {sub }} \leq \mathrm{T}_{\text {soften }}$ ) is much more relevant, as the wipe tests showed that the extensive flow and stress relaxation could be achieved. The substrate temperature was raised to $520^{\circ} \mathrm{C}$ during deposition, which is close to the Tg of Glass G. As expected, this gave a strong Glass G - steel bond (Figure 4) due to improved particle flow. However, cracking occurred at the interface of Glass P1 - Glass G (Figure 4), resulting in the delamination of Glass P1 from Glass G at room temperature. This was unexpected. Subsequent inspection of Figure 1b, showed there was a temperature drop (from $650^{\circ} \mathrm{C}$ to $300^{\circ} \mathrm{C}$ ) at the surface of Glass $\mathrm{G}$ during the changeover of powders from $\mathrm{G}$ to $\mathrm{P}$. This resulted in poor particle flow of Glass P1 on the top surface of Glass $\mathrm{G}$ and hence weak interfacial bonding. In addition, it would result in a higher quenching stress as predicted in Figure 2. It was also observed that a significant degree of edge spallation of Glass G took place due to the higher cooling rate at the edges. The substrate was then pre-heated to $540{ }^{\circ} \mathrm{C}$ (which is the softening temperature of Glass $\mathrm{G}$ ) and the interlayer was re-heated to $480{ }^{\circ} \mathrm{C}$ (Tg of Glass P1) before applying Glass P1. This time, a much smaller amount of spallation at the edge of the top layer was observed on cooling to room temperature.

Finally, the substrate temperature was maintained at $540^{\circ} \mathrm{C}$ but, on this occasion, the reheating temperature of the interlayer was raised to $520^{\circ} \mathrm{C}$ (the softening temperature of Glass P1). Under this condition, a crack-free and well adhered double-layered coating of $1200 \mu \mathrm{m}$ total thickness was obtained with good surface finish as shown in Figure 5.

\subsection{Porosity}


Figure 5 reveals that the top layer (Glass P1) contains a large proportion of fine pores at a total porosity of $20 \mathrm{vol} \%$, which may compromise its properties. Examination of Figure 5 shows that the pores delineate the splat boundaries, which suggests that the pores originate from entrapped air during spraying, as there are also no internal pores within the feedstock powder particles (Figure 6). The pores cannot move through the molten splats at a substrate temperature of $540^{\circ} \mathrm{C}$ and so must collect at the boundaries of the splats. This section investigates the development of porosity in thermally sprayed glass coatings.

Glass P1 was milled down to two batches of powders designated as P2 and P3. There were thus three powders to investigate: P1 (the original as-received powder) together with the more refined P2 and P3 powders. Each powder possessed a different particle size and size distribution as shown in Figure 7. P1 powder has a wide particle size distribution while P2 and P3 have progressively sharper distributions with smaller amounts of fine particles (those smaller than $5 \mu \mathrm{m})$. P1 has $32 \%$ of particles smaller than $5 \mu \mathrm{m}$, P2 has $14 \%$ of particles smaller than $5 \mu \mathrm{m}$ and $\mathrm{P} 3$ has $2 \%$ of particles smaller than $5 \mu \mathrm{m}$. The statistical means of the particle populations in the powders represented by $\mathrm{D}_{50}(50 \%$ particles less than the mean value) are $25 \mu \mathrm{m}, 36 \mu \mathrm{m}$, and $58 \mu \mathrm{m}$ for P1, P2 and P3 respectively. Figure 6 gives SEM micrographs of polished cross sections of these powders and confirms the progressive reduction in fines from $\mathrm{P} 1, \mathrm{P} 2$ to $\mathrm{P} 3$. It also provides the significant conclusion that all the powder particles appear dense with no detectable inner pores.

The topcoat depicted in Figure 5 uses Powder P1 as a feedstock sprayed onto a bond coat G, which had been previously sprayed onto the steel substrate. Spraying trials were then carried out to investigate the effect of particle size distribution on the coating structure. Powders P1, P2 and P3 were sprayed onto the bond coat G of $200 \mu \mathrm{m}$ thickness and feedstock particle size range $45-75 \mu \mathrm{m}$. The double-layered coating in Figure 5 has a topcoat produced from Powder $\mathrm{P} 1$. There is a substantial volume fraction of pores and most are below $10 \mu \mathrm{m}$ in size. The 
pores are spherical, which indicates they were formed while the glass was molten as this would allow them to attain the observed minimum surface-energy shape.

Figure 8 suggests that there is an association between the amount of fines (particles below $5 \mu \mathrm{m})$ in the feedstock powder and porosity in the deposited coating. Figure 9 gives an SEM micrograph of the morphologies of splats after wipe testing Glass P1 powder. Although there was a significant variation of splat morphology within a given powder, a clear tendency was observed for small and poorly flowed splats in Powder P1 as shown in Figure 9. This is a clear consequence of the large population of fines in P1 (30\% of particles below $5 \mu \mathrm{m})$. In addition, the fine particles tended to stick together to form porous aggregates in the feedstock powder, which would be expected to be inefficiently heated in the flame. As a result, the fine particles would only attain relatively low temperatures and velocities. Figure 9 shows porous aggregations of small spherical particles (exhibiting little flow) alongside much larger particles that are separated and have flowed extensively. A further possible mechanism is that fine particles may cool faster during the later stages of their flight through the flame. As a result, fine particles in general tend to have low droplet temperatures on impact with the substrate, undergo low splat flow rates and, consequently, are responsible for the high porosities found in Glass P1 coatings (Figure 8). In contrast, coatings from the P3 feedstock powder with its small population of fines (Figures 6 and 7) produces dense low-porosity powders, as shown in Figure 10.

\subsection{Mechanical Properties}

(a) Coating-substrate adhesion 
The measured adhesion strengths of the double-layered coatings are given in Figure 11. The average bond strength of the coatings prepared with powder P1 was $7 \pm 2 \mathrm{MPa}$. The observed failure pattern after pull-off testing for this coating system was a mixed mode of $80 \%$ cohesive failure $(80 \%$ of the total area of the test surface is fracture occurring within the coating) and $20 \%$ adhesion failure (20\% of fracture occurring at the coating-substrate interface). The cohesive failure was observed to occur mostly within the P1 topcoat, which was attributable to its high porosity.

The pull-off strengths of coatings prepared with powder P2 and P3 were $14 \pm 2 \mathrm{MPa}$ and $12 \pm$ $2 \mathrm{MPa}$ respectively. This is a substantial achievement and represents a major increase in adhesion strength by the control of the feedstock powder and substrate temperature. The failure pattern after pull-off testing was adhesion failure at the Glass G - steel interface. There was no fracture between the bond coat Glass G and topcoat Glass P during pull-off testing.

(b) Hardness and Fracture Toughness

The microhardness values of the coatings are presented in Figure 12. The average hardness value of the three coating systems was similar. However, the coating produced with the P1 powder showed a wider scatter in the individual hardness values and a slightly lower average hardness than the other two (P2 and P3). This effect is attributed to the higher porosity of the P1 coating. The hardness of conventional enamel was measured for comparative purposes.

The conventional enamel was made by preparing a ground coat slip, applying it to a gritblasted steel substrate using a spray gun, drying and firing at a specified temperature $\left(900^{\circ} \mathrm{C}\right)$ in a furnace. A separately prepared cover coat slip was then applied on the ground coat surface, dried and fired at a lower temperature than the ground coat. The procedure was 
repeated until the desired glass thickness is attained (1-2mm). Hardness values of $590 \pm 16 \mathrm{HV}$ were measured for the combustion flame sprayed coating and $584 \pm 14 \mathrm{HV}$ for the conventional enamel. This indicates that there is no significant difference in hardness between the flame sprayed coatings and conventional enamel.

The fracture toughness of the glass coating was estimated using the Vickers indentation test in which indentations were made on polished cross-sections of the coatings under an applied load of $5 \mathrm{~N}$. Crack lengths were measured on ten indentations for each specimen and the fracture toughness $\mathrm{K}_{\mathrm{C}}$ was calculated using the following equation [13- 15]:

$K_{C}=0.079 \frac{P}{a^{3 / 2}} \log \left[\frac{4.5 a}{c}\right]$

where $\mathrm{P}$ is the applied load, $\mathrm{a}$ is the half-indentation diagonal and $\mathrm{c}$ is the radial crack length.

The value of fracture toughness of the combustion-flame sprayed glass coatings made from $\mathrm{P} 3$ powder was $1.12 \mathrm{MPa} \mathrm{m}^{0.5}$. For the purpose of comparison, a coating was made from the same glass powders powder by conventional enamelling and this provided a fracture toughness value of $1.22 \mathrm{MPa} \mathrm{m}^{0.5}$. This indicates that there is little significant difference between coatings produced using the two deposition processes.

\subsection{Implications for thermal-spray techniques}

A significant scientific point resulting from this study is the importance of the velocity and temperature of the thermal-spray jet because without the high values of these parameters, the coatings could not be formed at $540^{\circ} \mathrm{C}$. In particular, the coating shown in Figure 5 is formed at a viscosity of $10^{8} \mathrm{~Pa} \mathrm{~s}$, as it is deposited at the dilatometric softening temperature. In contrast, conventional oven enamelling requires a viscosity of $10 \mathrm{~Pa} \mathrm{~s}$, which is orders of magnitude lower and is achieved by using much higher temperatures in the range $800-$ $900^{\circ} \mathrm{C}$. The particle velocities imposed by thermal spraying and the resulting impact forces, 
therefore, induce the flow of glass and form dense coatings at $540^{\circ} \mathrm{C}$ rather than the temperature range of $800-900^{\circ} \mathrm{C}$ that is needed for traditional enamelling. Consequently, glass coatings can be produced by thermal spraying at much lower substrate temperatures than those experienced in conventional enamelling and so greatly reduce any thermal damage.

Moreover, the enhancement of flow by the impact forces in thermal spraying is expected to enable the deposition of higher viscosity glasses than possible in the conventional enamelling process. This provides the potential of depositing a wider range of glass compositions with the possibility of enhanced properties and new products. The research also has possible application to high-temperature materials in the $\mathrm{Y}_{2} \mathrm{O}_{3}-\mathrm{Al}_{2} \mathrm{O}_{3}-\mathrm{SiO}_{2}$ system as, for example, investigated by the authors in previous research [16].

A further inference from these results is that thermal-spray techniques with higher velocity and temperature jets than those of combustion flame used in this investigation may produce coatings with enhanced glass flow or the same flow at lower substrate preheating temperatures. Table 2 shows very approximate velocities and temperatures for the jets in the main available processes $[9,11,12]$. Higher velocities will promote the flow of the glass by increasing the force on impact with the substrate, while higher temperatures will promote flow by reducing the viscosity. Both the velocity and temperature of the thermal-spray jet are therefore expected to increase splat flow but there are no quantified data. In general, the data indicate that all the other thermal-spray techniques have higher temperatures and velocities than the combustion-flame jet used in this paper. Limited work has been carried out on other techniques and, for example, plasma spraying has been shown to deposit glass coatings successfully $[5,8]$. However, although these higher energy processes clearly have potential, no direct comparisons of coating properties have been carried out and they are likely to be more expensive. 


\section{Conclusions}

The delamination of thick flame-sprayed glass coatings is due to the development of high quenching stresses at coating-substrate interface. Pre-heating the substrate surface to the dilatometric softening temperature of the glass substantially reduced the residual stress at the interface and improved interfacial bonding. The removal of fine particles from the glass feedstock powder substantially reduced the porosity of the coating. Control of the substrate temperature and feedstock particle distribution was found to double the adhesion strength of combustion-flame sprayed coatings. The fracture toughness and hardness of the combustionflame sprayed glass coatings were very similar to those of conventional enamel coatings made by oven fusing the same feedstock powder. A double-layered dense glass coating with $1200 \mu \mathrm{m}$ of thickness was successfully deposited using combustion-flame spraying by control of the substrate temperature and feedstock powder distribution.

\section{Acknowledgements}

The authors would like to thank the Directorate-General for Science, Research and Development of the European Commission for financial support of the research and Pfaudler Werke GmbH for providing the glass powder.

\section{References}

1. A.I. Andrews, Porcelain Enamels: "The Preparation, Application, and Properties of Enamels", 2nd edition Garrard Press, Champaign (IL), 1961.

2. K.A. Maskall, D. White, Vitreous Enamelling, $1^{\text {st }}$ edition Pergamon Press, Oxford, 1986.

3. L. Samiee, H. Sarpoolaky and A. Mirhabibi, Microstructure and adherence of cobalt containing and cobalt free enamels to low carbon steel. Materials Science \& Engineering A, 458 (2007) 88-95 
4. Y. Bao, T. Zhang, D.T.Gawne, Non-steady state heating of substrate and coating during thermal-spray deposition, Surface \& Coatings Technology 194 (2005) 82-90

5. T. Zhang, Y. Bao and D.T. Gawne, Process model of plasma enamelling, Journal of European Ceramic Society, 23 (2003) 1019-1026

6. Y. Bao, D.T. Gawne, J Gao, T Zhang, B. Cuenca and A. Alberdi, Thermal-spray deposition of enamel on aluminium alloys, Surface \& Coatings Technology, 232 (2013) 150-158

7. J.A. Picas, A. Forn, R. Rilla, E. Martin, HVOF thermal sprayed coatings on aluminium alloys and aluminium matrix composites. Surface \& Coatings Technology, 200 (2005) 11781181

8.V. Cannillo and A, Sola, Different approaches to produce coatings with bioactive glasses: enamelling vs plasma spraying, Journal of European Ceramic Society, 30 (2010) 2031-2039

9. L. Pawlowski, The Science and Engineering of Thermal Spray Coating, John Wiley,

New York, NY, 2008, 68.

10. J. E. Shelby, Introduction to Glass Science and Technology, Cambridge, Second Edition, Royal Society of Chemistry, 2005, 112.

11. P.L. Fauchais, J.V.R. Heberlein, M.L. Boulos, Thermal Spray Fundamentals, Springer, New York, 2014.

12. M.R. Dorfman, Thermal spray: basics, processes, materials and applications, Advanced Materials and Processes, July 2002, ASM International, ISSN 0882-7958, OCLC 11981589, pp47-68.

13. Evans, A. G. and Wilshaw, T. R., Quasi-static solid particle damage in brittle solids: 1. Observations, analysis and implications, Acta Metallurgica, 1976, 24, 939-956.

14. Bolelli, G., Lusvarghi, L., Manfredini, T., Parsini, E., Siligardi, C., BAS, CMAS and CZAS glass coatings deposited by plasma spraying, Journal of the European Ceramic Society, 2007, 27(3), 4575-4588.

15. P. Chantikul, P. G.R. Anstis, B.R.Lawn, D.B.Marshall, (1981), A critical evaluation of indentation techniques for measuring fracture toughness, J. Am. Ceram. Soc. 64, 539-543.

16. Y. Bao, T. Zhang, D.T. Gawne, P. Mason, "Quantitative model for the viscous flow and composition of two-phase silicon nitride-based particles in plasma-spray deposition", Journal of the European Ceramic Society, 28 (2009) 1521-1528. 
Table I. Thermal properties of Glasses P and G.

\begin{tabular}{|l|l|l|l|}
\hline Glass & Softening temperature, & Glass transition & Thermal expansion coefficient \\
& $T_{\text {soft }} /{ }^{\circ} \mathrm{C}$ & temperature, $\mathrm{Tg} /{ }^{\circ} \mathrm{C}$ & $\left(20-400^{\circ} \mathrm{C}\right), \alpha / \mathrm{K}^{-1}$ \\
\hline Glass P1 & 524 & 480 & $8.9 \times 10^{-6}$ \\
\hline Glass G & 540 & 516 & $9.7 \times 10^{-6}$ \\
\hline Steel & & & $13.6 \times 10^{-6}$ \\
\hline
\end{tabular}

Table II. Approximate temperatures and velocities of thermal-spray jets $[9,11,12]$

\begin{tabular}{|l|l|l|l|}
\hline Technique & Jet temperature, & Particle impact velocity, & Relative process cost \\
& ${ }^{\circ} \mathrm{C}$ & $\mathrm{m} / \mathrm{s}$ & \\
\hline Combustion flame powder & 2500 & 50 & 3 \\
\hline Combustion flame wire & 2800 & 180 & 3 \\
\hline High-velocity oxy-fuel & 3100 & $400-800$ & 5 \\
\hline Wire arc & 4500 & 200 & 1 \\
\hline Atmospheric plasma & 10000 & 300 & 5 \\
\hline Vacuum plasma & 10000 & 450 & 10 \\
\hline
\end{tabular}




\section{$\underline{\text { List of figure captions }}$}

Figure 1. Measured thermal histories of coatings and interface during thermal spraying: (a) temperature trace at Glass G coating surface followed by that at Glass P1 coating surface; (b) temperature trace at the surface of Glass $\mathrm{G}$ coating and at the coating-substrate interface.

Figure 2. Calculated quenching stress of the glass coatings during deposition. The temperatures next to the curves are coating-substrate interface temperature

Figure 3. Morphologies of impinging glass particles $(\mathrm{P} 1)$ on a polished steel substrate of different temperatures. a: $25^{\circ} \mathrm{C}$; b: $500^{\circ} \mathrm{C}$; c: $540^{\circ} \mathrm{C}$; d: $700{ }^{\circ} \mathrm{C}$

Figure 4. SEM micrograph showing the cross-section of double layered glass coating on steel.

Figure 5. SEM micrograph showing the cross- section of double-layered glass coating with a P1 top coat and G bond coat

Figure 6. SEM micrographs of polished cross-section of powders P1, P2 and P3

Figure 7. Particle size and size distribution of three powders: P1, P2 and P3.

Figure 8. Comparison of porosity for various coatings deposited with different powders

Figure 9. Morphologies of the Glass P 1 splats on a polished steel surface produced by wipe test. The steel surface was preheated to $500^{\circ} \mathrm{C}$ before wipe tests.

Figure 10. SEM micrograph showing a polished cross-section of a double-layered P3 glass coating

Figure 11 Measured pull-off strength of glass coating by using top coat powders: P1, P2 and P3

Figure 12 Measured microhardness values of the topcoats by thermal spraying 


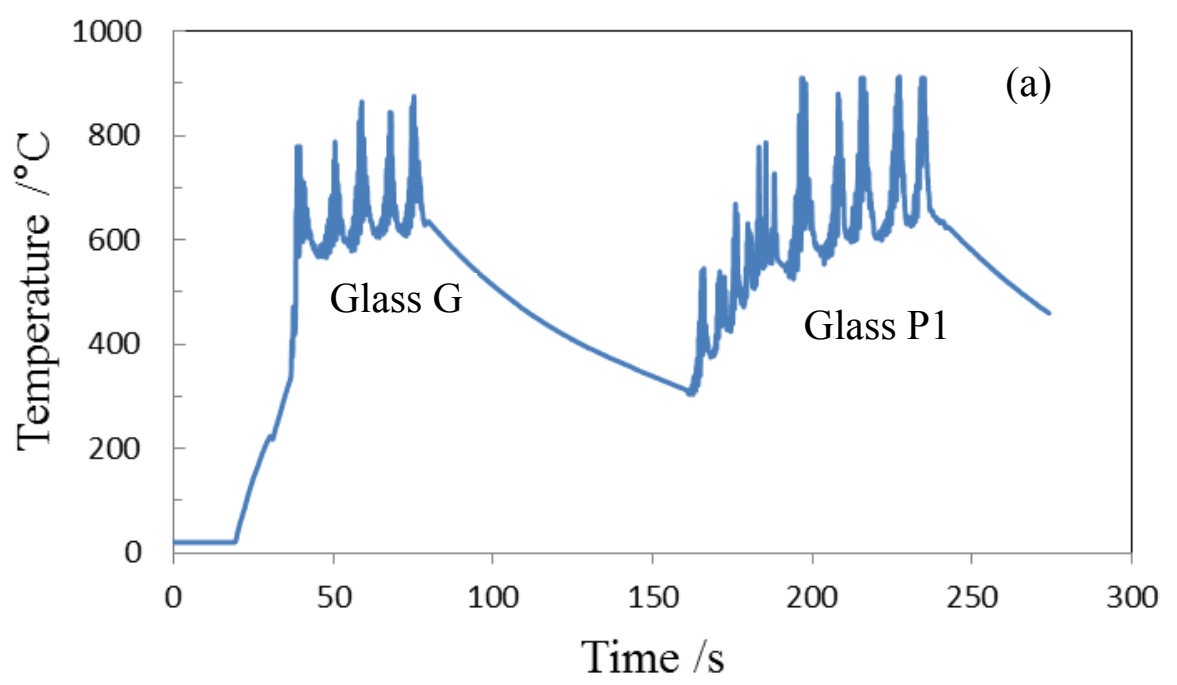

Figure 1a

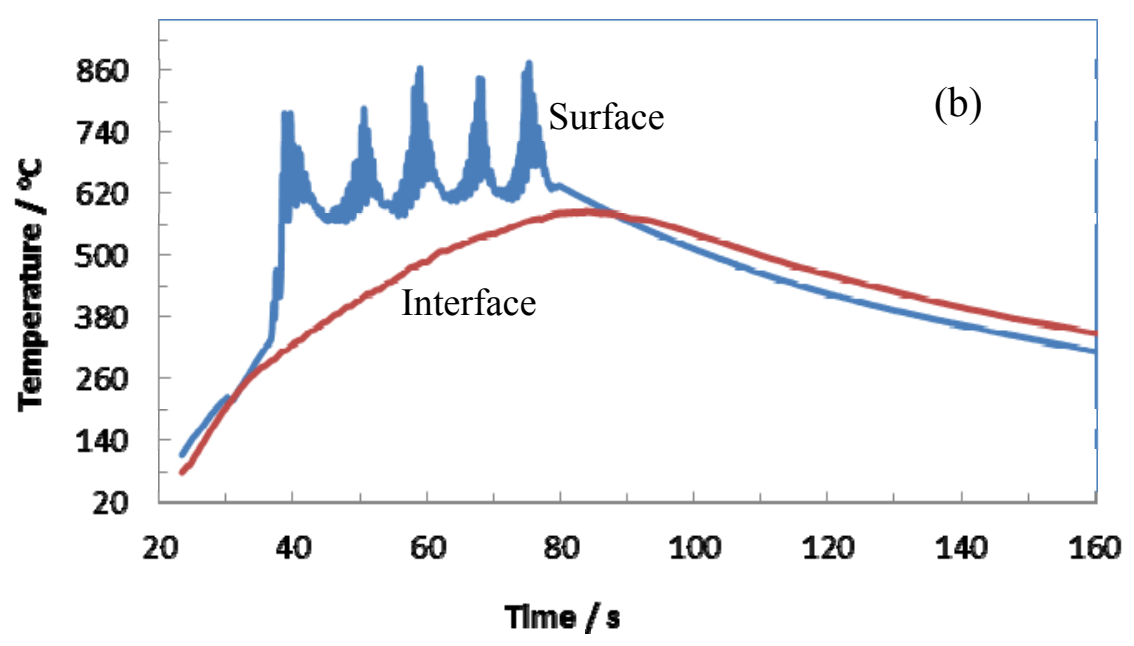

Figure 1b 


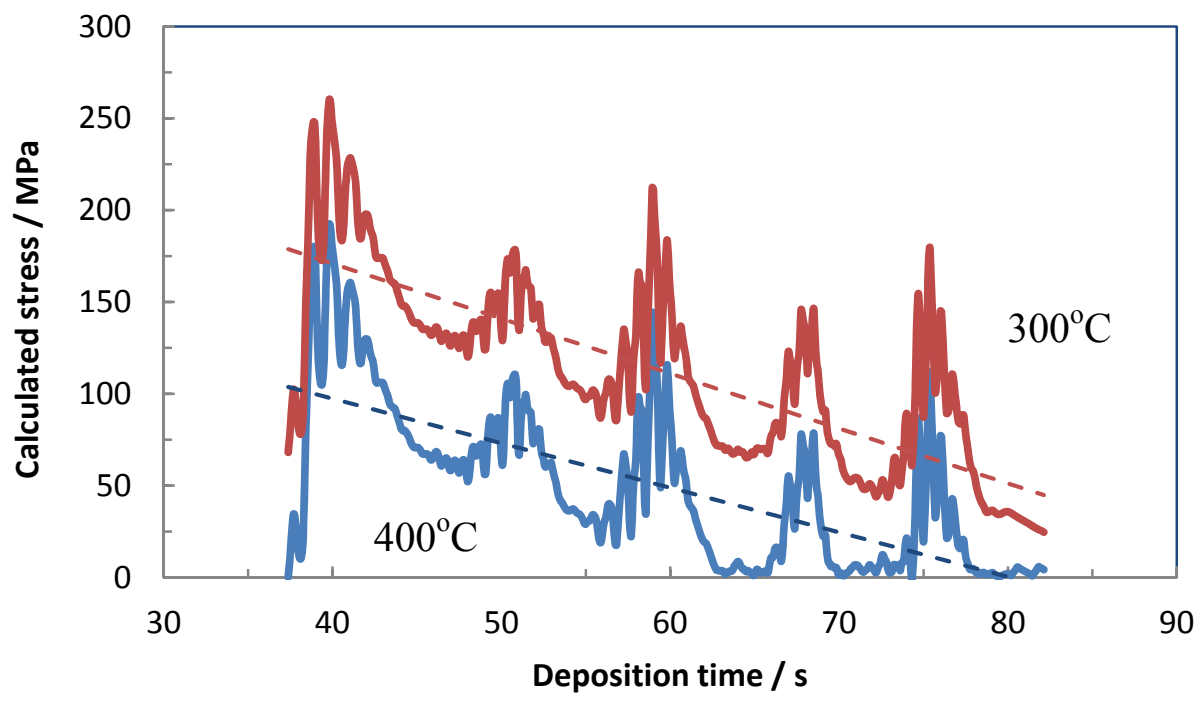

Figure 2
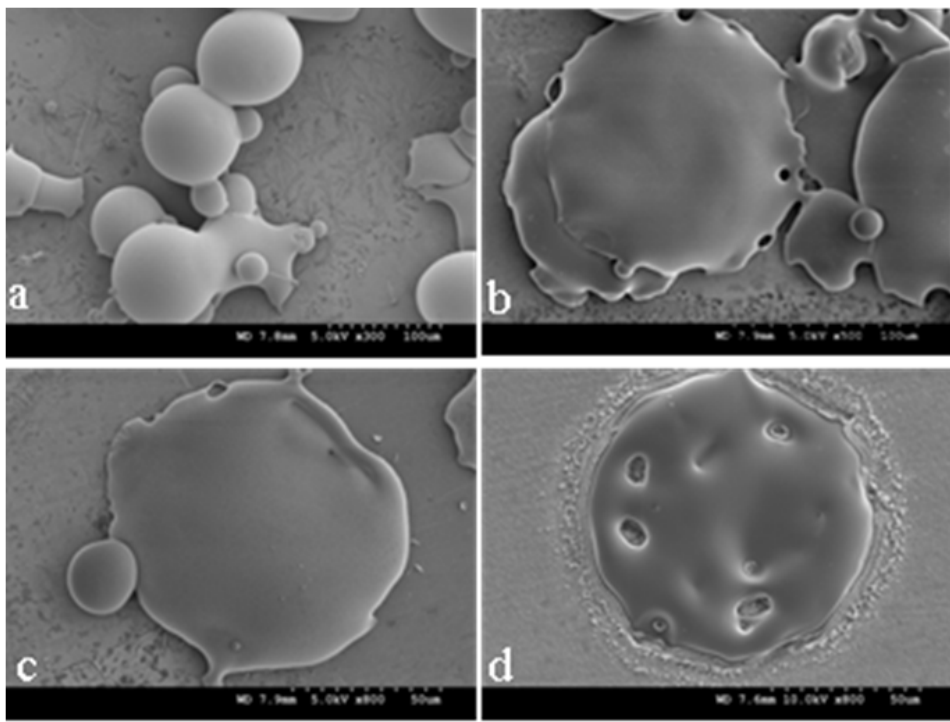

Figure 3 


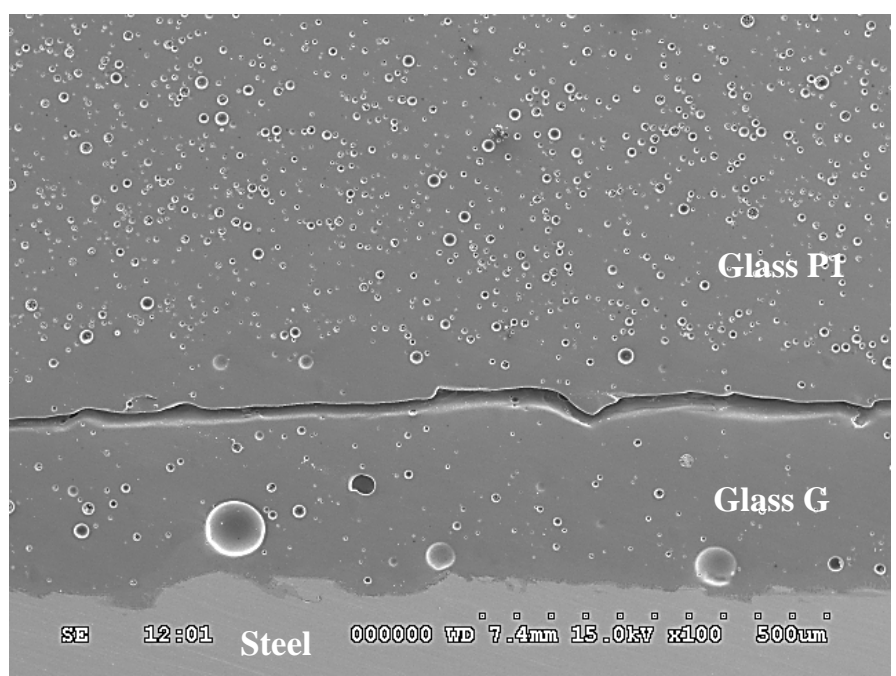

Figure 4

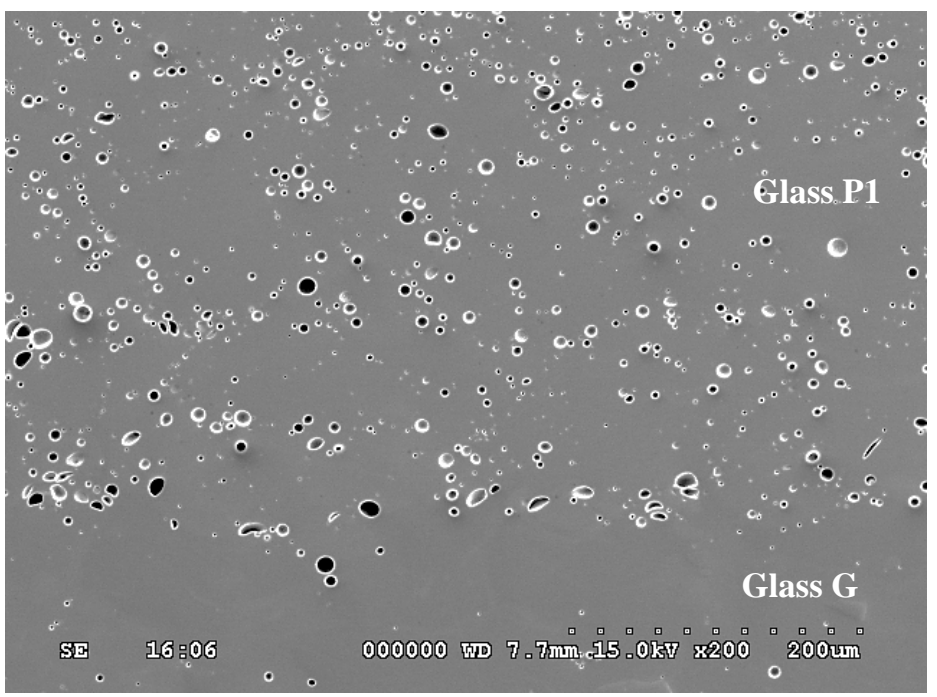

\section{Figure 5.}



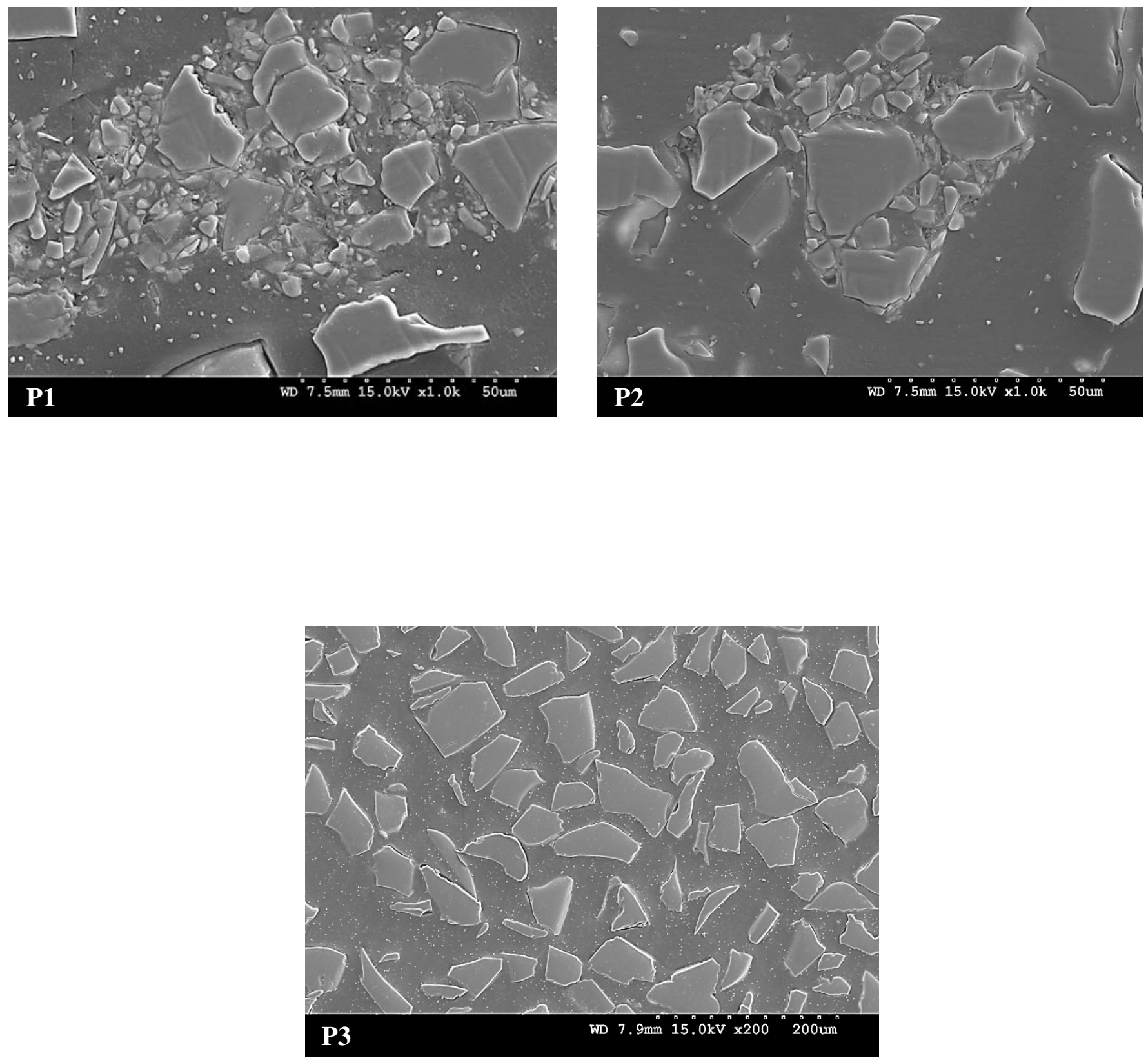

Figure 6 

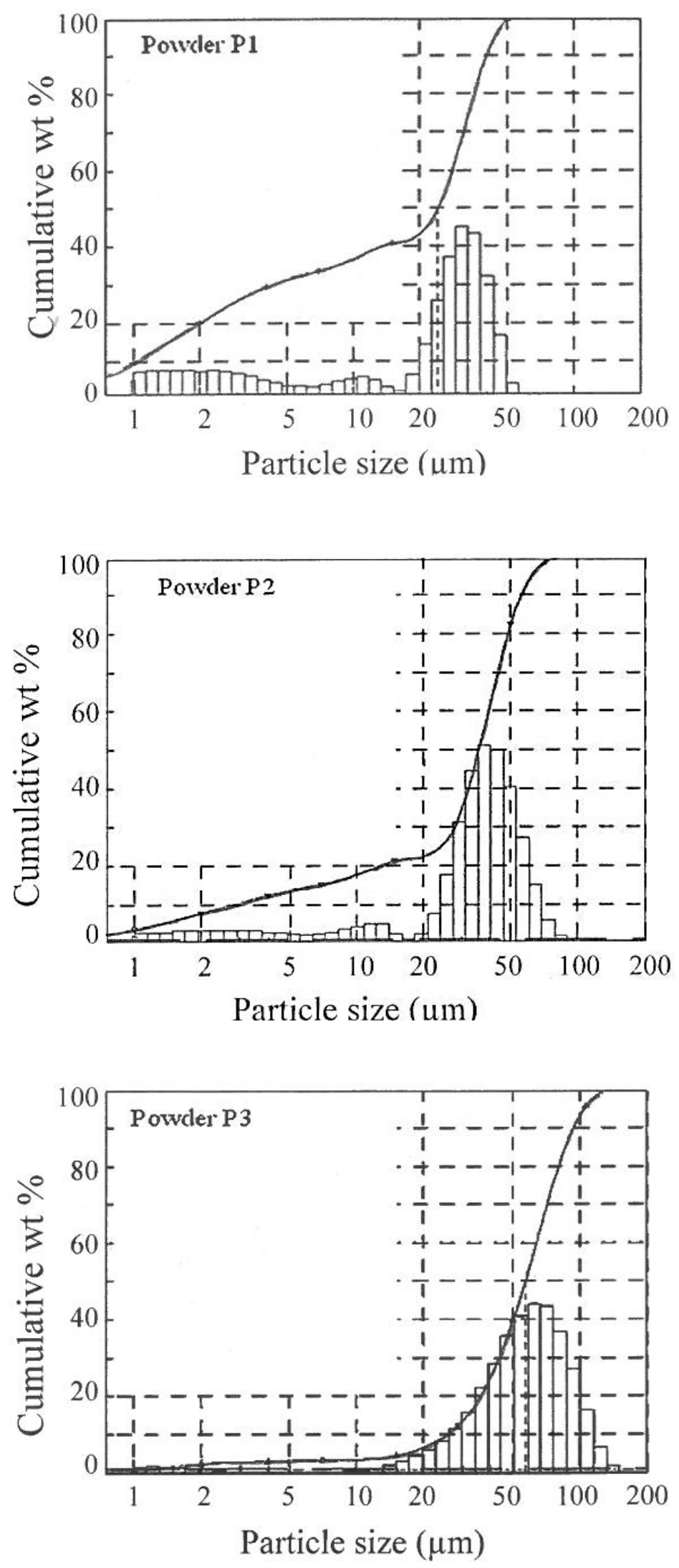

Figure 7. 


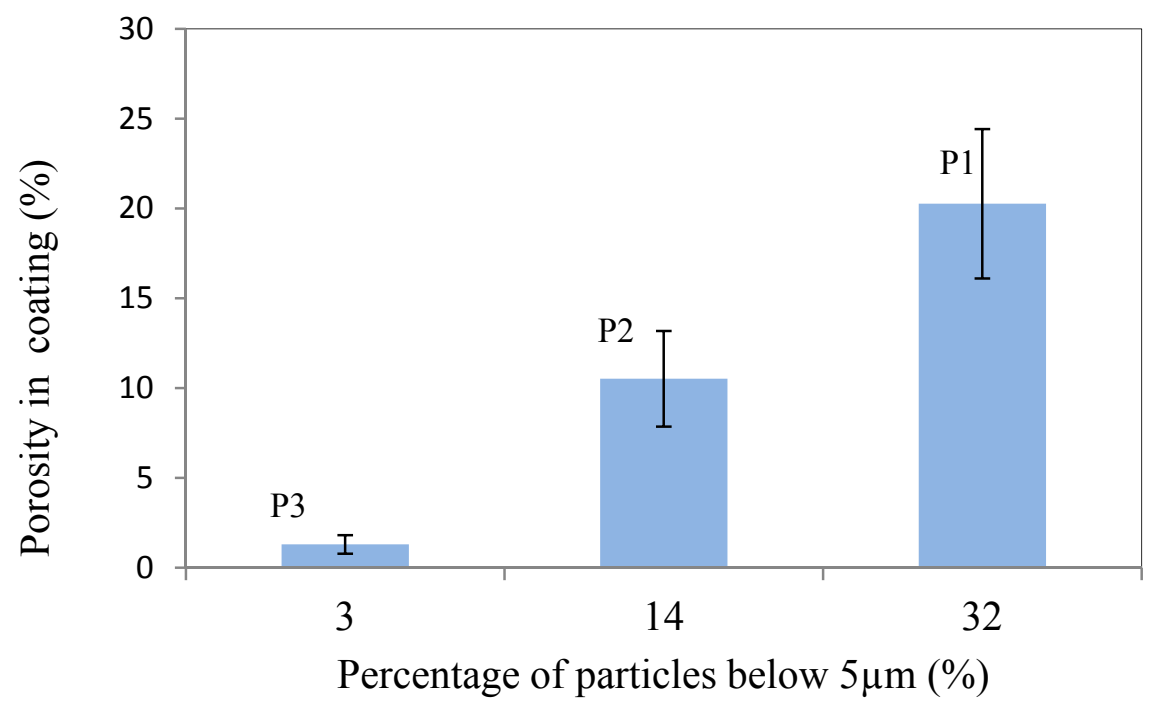

Figure 8.

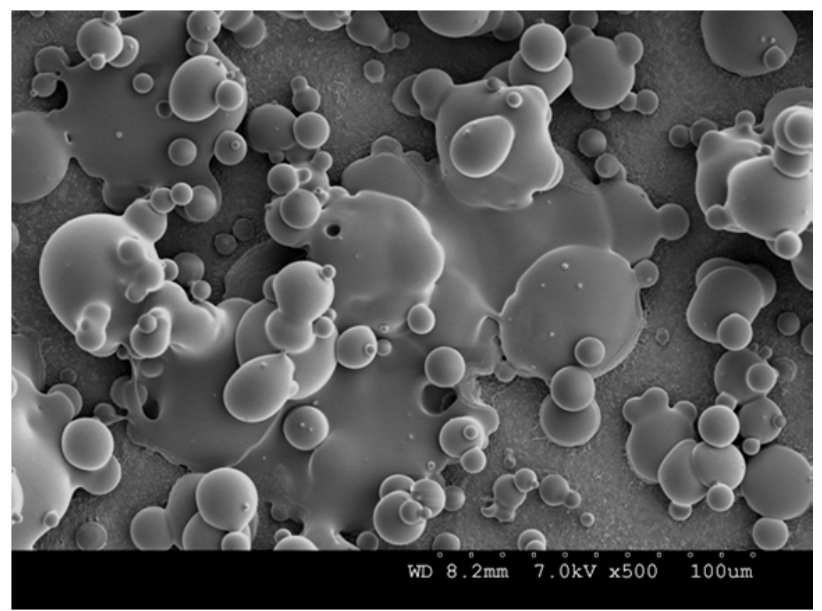

Figure 9. 


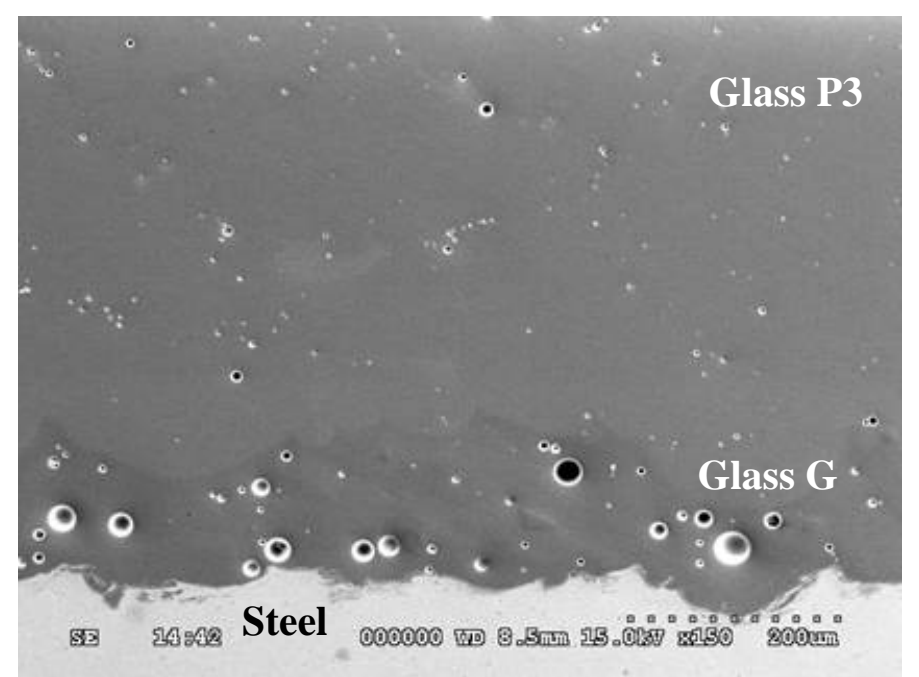

Figure 10.

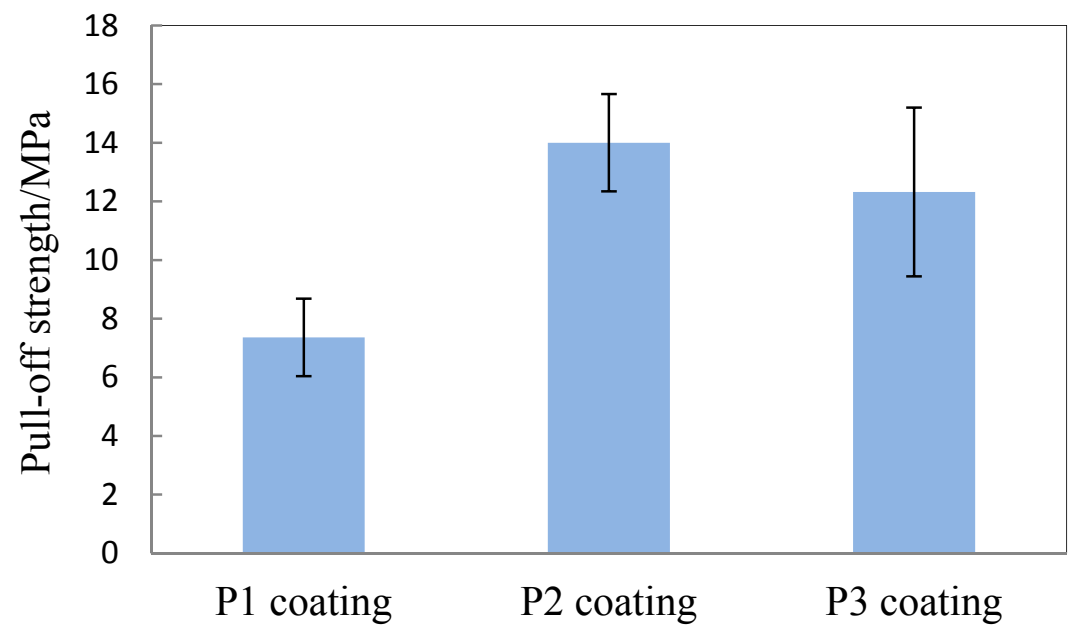

Figure 11 


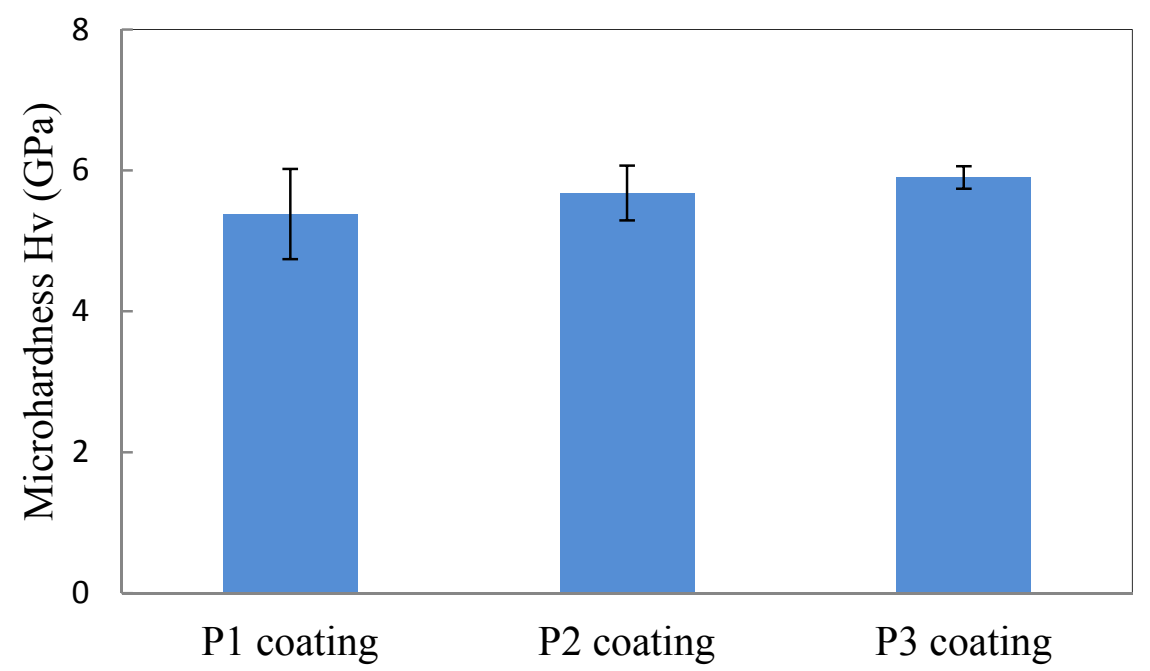

Figure 12. 